\title{
COVID-19 DOESN'T NEED LOCKDOWNS TO DESTROY JOBS: THE EFFECT OF LOCAL OUTBREAKS IN KOREA
}

\author{
Sangmin Aum \\ Sang Yoon (Tim) Lee \\ Yongseok Shin \\ Working Paper 27264 \\ http://www.nber.org/papers/w27264
}

\author{
NATIONAL BUREAU OF ECONOMIC RESEARCH \\ 1050 Massachusetts Avenue \\ Cambridge, MA 02138 \\ May 2020
}

The views expressed herein are those of the authors and do not necessarily reflect the views of the National Bureau of Economic Research.

NBER working papers are circulated for discussion and comment purposes. They have not been peer-reviewed or been subject to the review by the NBER Board of Directors that accompanies official NBER publications.

(C) 2020 by Sangmin Aum, Sang Yoon (Tim) Lee, and Yongseok Shin. All rights reserved. Short sections of text, not to exceed two paragraphs, may be quoted without explicit permission provided that full credit, including $\odot$ notice, is given to the source. 
COVID-19 Doesn't Need Lockdowns to Destroy Jobs: The Effect of Local Outbreaks in Korea Sangmin Aum, Sang Yoon (Tim) Lee, and Yongseok Shin

NBER Working Paper No. 27264

May 2020

JEL No. I14,I18,J21

\begin{abstract}
$\underline{\text { ABSTRACT }}$
Unlike most countries, Korea did not implement a lockdown in its battle against COVID-19, instead successfully relying on testing and contact tracing. Only one region, Daegu-Gyeongbuk (DG), had a significant number of infections, traced to a religious sect. This allows us to estimate the causal effect of the outbreak on the labor market using difference-in-differences. We find that a one per thousand increase in infections causes a 2 to 3 percent drop in local employment. Noncausal estimates of this coefficient from the US and UK, which implemented large-scale lockdowns, range from 5 to 6 percent, suggesting that at most half of the job losses in the US and UK can be attributed to lockdowns. We also find that employment losses caused by local outbreaks in the absence of lockdowns are (i) mainly due to reduced hiring by small establishments, (ii) concentrated in the accommodation/food, education, real estate, and transportation industries, and (iii) worst for the economically vulnerable workers who are less educated, young, in low-wage occupations, and on temporary contracts, even controlling for industry effects. All these patterns are similar to what we observe in the US and UK: The unequal effects of COVID-19 are the same with or without lockdowns. Our finding suggests that the lifting of lockdowns in the US and UK may lead to only modest recoveries in employment unless COVID-19 infection rates fall.
\end{abstract}

Sangmin Aum

Myongji University

34 Geobukgol-ro, Seodaemun-gu

Seoul 03674

South Korea

aumsang@gmail.com

Sang Yoon (Tim) Lee

Queen Mary University of London

Mile End Road

E1 4NS London

United Kingdom

and CEPR

sylee.tim@qmul.ac.uk
Yongseok Shin

Department of Economics

Washington University in St. Louis

One Brookings Drive

St. Louis, MO 63130

and NBER

yshin@wustl.edu 
We isolate the economic effect of COVID-19 that operates through the fear of infection: The fact that people hunker down and curtail economic activity in response to local outbreaks. Our estimate is not contaminated by the concomitant effect of government-mandated lockdowns or supply and demand shortages from outside the economy (such as inter-regional and international trade) due to the epidemic. We estimate the effect on overall employment, hires and separations, and also examine how the effect is distributed across industries and across workers of different occupation, education, age, gender and employment type.

Our estimation exploits exogenous regional variation in the COVID-19 outbreak in Korea, as well as the absence of mandatory lockdowns or other socialdistancing measures imposed by the government. ${ }^{1}$ South Korea had only 30 confirmed infections prior to February 18, 2020, when "Patient 31" attended a religious gathering of the "Shincheonji" sect in Daegu, a metropolitan city in the Gyeongbuk province. By February 29, the number of cases in Korea had exploded to 3,150, with 2,724 cases (or 86.4 percent) in the Daegu-Gyeongbuk region (DG hereafter) alone. Of these, more than 60 percent were traced to Shincheonji. Figure 1 shows the cumulative COVID-19 infections per thousand on February 28 and March 15. It is not the case that DG was more susceptible to the Shincheonji sect, which has members and churches spread all over Korea. Thus, the regional variation in infections is uncorrelated with any underlying socioeconomic factor and provides grounds for a natural experiment. ${ }^{2}$

Moreover, the Korean government chose intensive testing and contact tracing as their tool for containing the epidemic rather than enhanced social distancing, and never mandated a lockdown. This resulted in two additional advantages of our estimation strategy: (i) The economic reactions were not prescribed by the government's promulgation of what are essential or non-essential economic activities, unlike in the vast majority of countries, and (ii) As of May 20, the success of its containment strategy resulted in a very low cumulative infection rate of 0.06 per thousand in Korea, excluding DG, ensuring that the direct effect

\footnotetext{
${ }^{1}$ Another celebrated example of a country not implementing a lockdown is Sweden, and researchers have tried to infer the economic effect of lockdowns by comparing Sweden with other countries (Andersen et al., 2020; Born et al., 2020). By design, such studies cannot recover the direct, causal effect of the pandemic and at best, can only estimate the effect of a lockdown. But even the lockdown effects are still subject to omitted variable bias and endogeneity - lockdowns are a choice variable for the government, not an exogenous variation across countries. In addition, Sweden has a much higher cumulative infection rate (3.2 per thousand as of May 20) than some of the comparison countries (e.g., Denmark, 1.9 per thousand), rendering a simple comparison of economic outcomes less informative.

${ }^{2}$ The DG region comprises about 10 percent of South Korea's total population of 52 million and about 9 percent of national GDP.
} 
Fig. 1: Confirmed COVID-19 infections across administrative regions

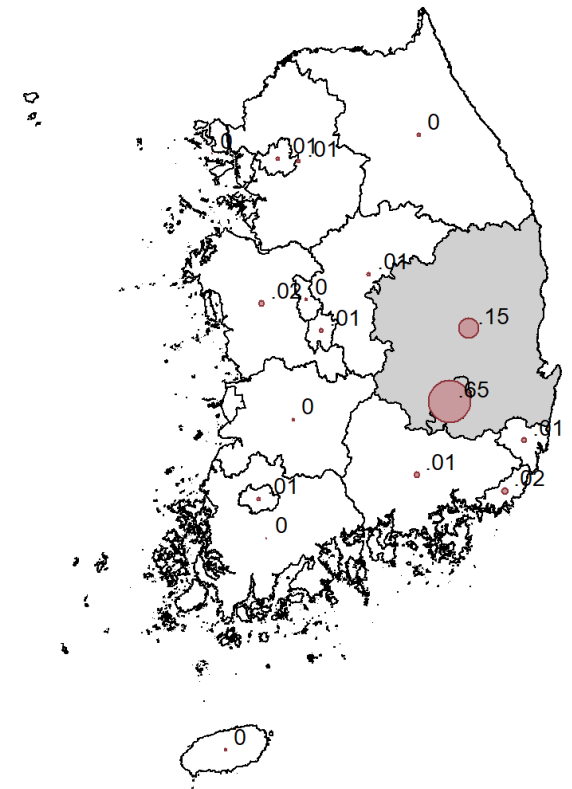

(a) February 28, 2020

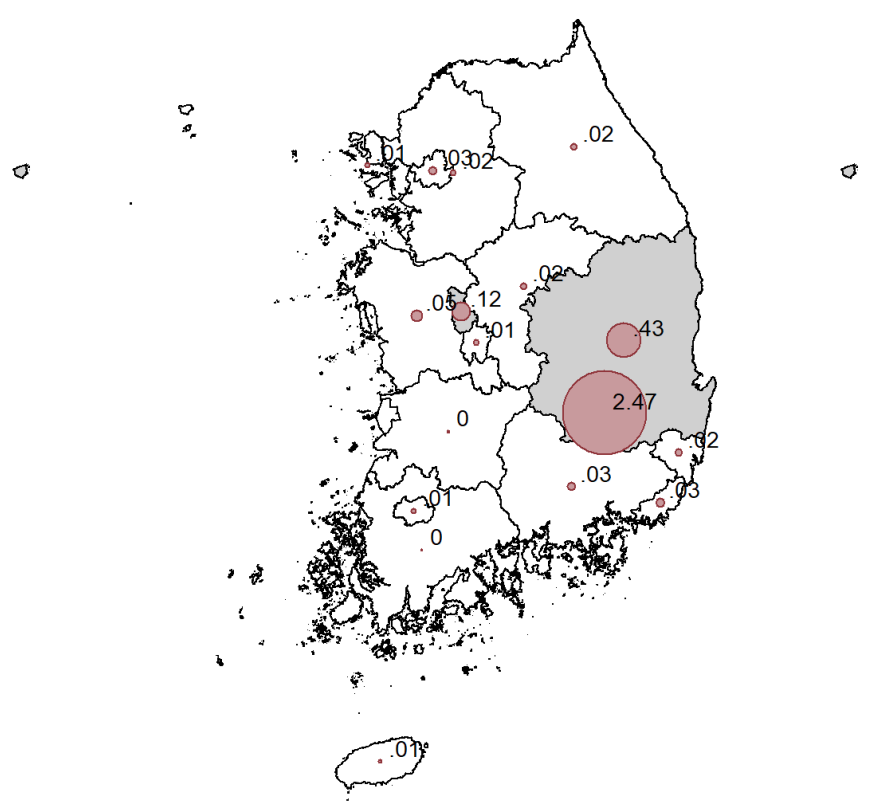

(b) March 15, 2020

Notes: Circle sizes represent cumulative infection cases per thousand. Regions with more than 0.1 cumulative cases per thousand are shaded in gray. The city of Daegu has the largest circle and the gray region with the second largest circle is the province of Gyeongbuk.

Source: KCDC

is entirely confined to DG, with a rate of 1.6 per thousand.

We exploit this setting using difference-in-differences (DiD) on data from an establishment survey and a separate household survey. The scheme captures the causal effect of the outbreak on local employment relative to the rest of the country. The establishment survey further allows a breakdown by industry and by establishment size. The household survey further allows a breakdown by occupation, education, age, gender and employment type.

Results Our causal estimate implies that a one per thousand increase in infections leads to a 2 to 3 percent drop in local employment in the absence of lockdowns. In comparison, non-causal estimates of this coefficient for the United States or United Kingdom, which implemented large-scale lockdowns, range from 5 to 6 percent, suggesting that about half of their job losses may be due to voluntary reductions in economic activity by private businesses and consumers, rather than a consequence of government-mandated lockdowns. Alternatively, at most half the job losses in the US and UK can be attributed to lockdowns.

Employment losses caused by local outbreaks stem mostly from reduced hir- 
ing by businesses and are mirrored by a rise in labor market non-participation rather than unemployment. By industry, losses are concentrated in the accommodation/food, education, real estate, and transportation industries, similar to (non-causal) patterns observed in the US and UK.

The causal effects of the COVID-19 shock without lockdowns are very unequally distributed: More or less all employment losses were accounted for by small establishments (fewer than 30 employees), while large establishments actually grew. Less-educated workers, the young, workers in low-wage occupations and on temporary contracts, and the self-employed lost the most jobs to the COVID-19 shock, even controlling for industry effects. In a nutshell, the most economically vulnerable groups even before the shock experienced the most dire effects. By gender, although the COVID-19 shock hit industries in which women are over-represented harder, the within-industry effect was positive for women while negative for men. Consequently, the total causal effect destroyed more jobs for men than for women. ${ }^{3}$ All these patterns of causal effects except the effects by gender are similar to what we observed in the US and UK: The unequal effects of COVID-19 are the same with or without lockdowns.

Our finding that lockdowns account for at most half the job losses in the US and UK suggests that the lifting of lockdowns may lead to only modest recoveries in employment absent larger reductions in COVID-19 infection rates.

Of course, this is not to say that lockdowns are the best policy response. They are a very blunt tool and may cause more economic damage than necessary. Using a more theoretical approach, Aum et al. (2020) shows that targeted approaches can more effectively contain the epidemic at a lower economic cost.

\section{Data}

We use three data sets. The first is the Labor Force Survey at Establishments (LFSE), a monthly survey of 40,000 sampled employers (out of 4.1 million in 2018) by the Ministry of Employment and Labor. It reports the number of employees and vacancies as of the last business day of the month, as well as the number of new hires and separations for the month. The second is the Economically Active Population Survey (EAPS), a monthly survey of 35,000 households collected around the 15th of each month by Statistics Korea, which

\footnotetext{
${ }^{3}$ Nationwide, the drop in women's employment was larger than men's in Korea as well, even in the absence of a lockdown.
} 
includes worker characteristics (education, age, gender) and jobs (occupation and employment type). ${ }^{4}$ The last is the number of confirmed COVID-19 cases over time published by the Korea Centers for Disease Control (KCDC).

Fig. 2: COVID-19 infections per thousand population

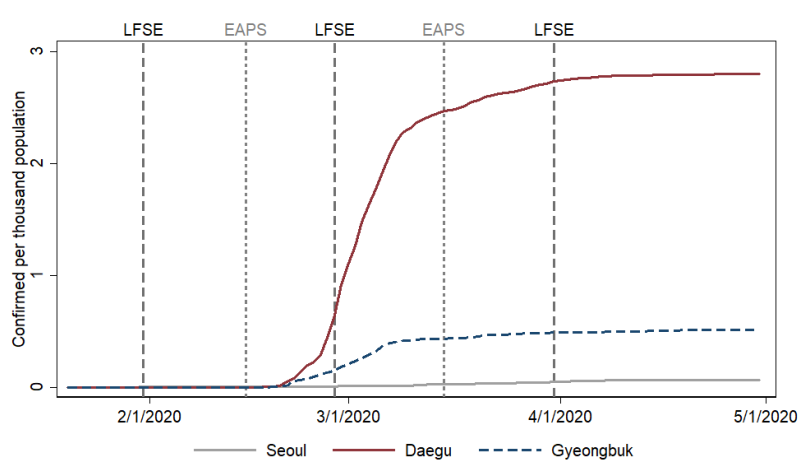

(a) Survey dates

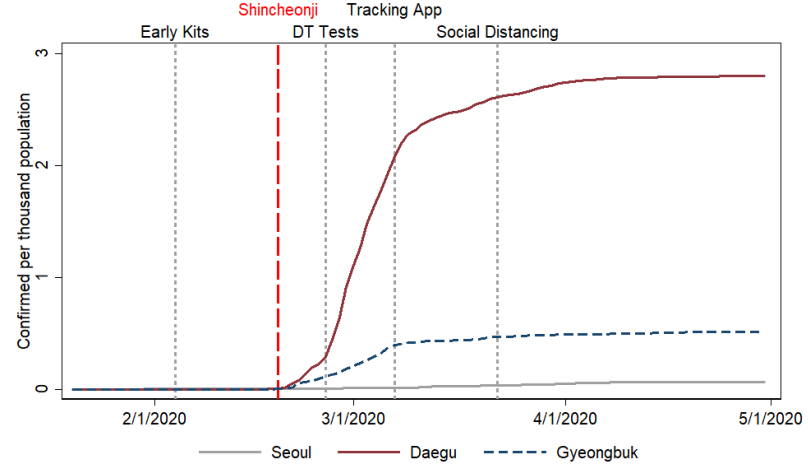

(b) Policy measures

Notes: The curves are the cumulative confirmed infections per thousand in Seoul, the capital with 9.8 million people, (gray solid), Daegu (red solid) and Gyeongbuk (dashed). In the left panel, survey dates are marked by vertical lines: LFSE on the last business day of each month and EAPS around the 15th of each month. The right panel shows the government policy timeline: (i) February 4, early authorization of diagnostic testing kits; (ii) February 26, installation of drive-through test and screening centers; (iii) March 7, launch of a self-quarantine tracking smartphone app (iv) March 22: social distancing advisory campaign. The government also mandated schools and universities to delay the beginning of the academic year on March 2, 2020.

Source: KCDC, Ministry of Employment and Labor, Statistics Korea.

\section{Methodology and Estimation Results}

The DiD scheme we use requires treatment to be exogenous to outcomes, and a parallel trends assumption to hold between comparison groups pre-treatment. In our case, the treatment is DG having experienced a major outbreak, which was traced to local Shincheonji gatherings. Shincheonji is a popular yet secretive religious sect, but from what we know, has more than 200,000 members spread out across Korea regardless of each region's economic standing. If anything, the DG region has less followers per capita than other regions. Thus, the epidemic variation can be considered exogenous.

Economically, DG's share of national GDP and employment has been stable for at least the last three years, as well as its share of international trade. In any

\footnotetext{
${ }^{4}$ Respondents' region is not available in the public-use microdata, but Statistics Korea provides detailed summary tables by province.
} 
case, Korean exports and imports were in fact higher in February to March 2020 than the monthly average throughout 2019, so it is unlikely that our results are driven by international factors, especially the contraction of the Chinese economy. Moreover, to alleviate concerns that differences in industrial or demographic composition across regions may introduce nonparallel pre-trends, and also to disaggregate COVID-19's causal effects, our cross-regional analysis is performed not only on the entire sample for each of our data sources, but also by industry and by demographic group.

We present three sets of estimates using DiD, using LFSE data as of February 28 and March 31, and EAPS data as of March 15. Since the Korean government closed schools on March 2 and commenced social distancing campaigns on March 22 , later estimates may be biased; that is, both labor market outcomes and the spread of the epidemic are endogenous to government policy. Nonetheless, at no point did the government suggest the possibility of a lockdown, so all our estimates are free of potentially large-scale disruptions.

\subsection{Establishment-side employment data (LFSE)}

We first focus on the LFSE data as of February 28, nine days after the Shincheonji outbreak. At this point, the Korean government is yet to implement any social distancing measures, instead relying exclusively on contact tracing, testing, and quarantine of the confirmed infected. Given the exogenous regional variation in confirmed infections and the timing of the survey, we estimate the causal effect of the outbreak on the labor market using the following DiD specification:

$$
y_{r, t}^{i}=\beta_{0}^{i}+\beta_{1}^{i} \cdot D_{r}(\mathrm{DG})+\beta_{2}^{i} \cdot D_{t}(\mathrm{Feb})+\gamma^{i} \cdot D_{r}(\mathrm{DG}) \cdot D_{t}(\mathrm{Feb})+\varepsilon_{r, t}^{i},
$$

where $y_{r, t}^{i}$ is the variable of interest for industry $i$, region $r$ at month $t, D_{r}(\mathrm{DG})$ is a dummy variable that equals 1 if $r=\mathrm{DG}$ and 0 otherwise, and $D_{t}$ (Feb) equals 1 if $t$ is February 2020 or later months, and 0 otherwise. The primary coefficient of interest is the DiD term $\gamma^{i}$, designed to capture the effect on the DG region, which was the lone hot spot. In some cases, we will compare $\gamma^{i}$ with $\beta_{2}^{i}$, the effect of the epidemic on the country as a whole, which we cannot interpret as causal but is still informative as it is uncontaminated by government-led lockdowns.

We report estimation results for employment growth from January to February and from January to March in Table 1. We estimate the regression coefficients for the whole sample and also separately for the 18 different industries that span 
Table 1: COVID-19 effect on employment, total and by industry

\begin{tabular}{|c|c|c|c|c|c|c|c|c|}
\hline \multirow[b]{3}{*}{ Total } & \multicolumn{4}{|c|}{ Monthly till Feb 2020} & \multicolumn{4}{|c|}{ Bimonthly till March 2020} \\
\hline & $\beta_{2}$ & & $\gamma$ & & $\beta_{2}$ & & $\gamma$ & \\
\hline & $-0.89^{* * *}$ & $(0.09)$ & $-1.02^{* * *}$ & $(0.17)$ & $-2.08^{* * *}$ & $(0.20)$ & $-1.22^{* * *}$ & $(0.41)$ \\
\hline Accommodation, food svc. & $-5.70^{* * *}$ & $(0.14)$ & $-9.45^{* * *}$ & $(0.51)$ & $-13.19^{* * *}$ & $(0.37)$ & $-7.30^{* * *}$ & $(1.08)$ \\
\hline Facility mgmt., support, rental & $-0.98^{* * *}$ & $(0.11)$ & $-0.50^{*}$ & $(0.27)$ & $-2.83^{* * *}$ & $(0.28)$ & $1.36^{* * *}$ & $(0.48)$ \\
\hline Repair, other personal svc. & $-1.15^{* * *}$ & $(0.08)$ & $0.43^{*}$ & $(0.22)$ & $-3.17^{* * *}$ & $(0.19)$ & $-2.60^{* * *}$ & $(0.38)$ \\
\hline Real estate & $0.14^{*}$ & $(0.08)$ & $-1.25^{* * *}$ & $(0.22)$ & $-0.43^{* *}$ & $(0.19)$ & $-2.60^{* * *}$ & $(0.40)$ \\
\hline Health, social svc. & $-0.56^{* * *}$ & $(0.08)$ & $-1.03^{* * *}$ & $(0.14)$ & $-1.49^{* * *}$ & $(0.17)$ & $-3.41^{* * *}$ & $(0.28)$ \\
\hline Arts, sports, recreation & $-1.99^{* * *}$ & $(0.32)$ & 0.89 & $(0.68)$ & $-9.07^{* * *}$ & $(0.73)$ & -0.33 & $(1.70)$ \\
\hline Water, sewage, waste mgmt. & 0.05 & $(0.08)$ & $1.17^{* * *}$ & $(0.20)$ & 0.18 & $(0.18)$ & $0.85 *$ & $(0.44)$ \\
\hline Wholesale, retail & $-0.76^{* * *}$ & $(0.06)$ & -0.09 & $(0.30)$ & $-1.96^{* * *}$ & $(0.11)$ & $-1.81^{* * *}$ & $(0.57)$ \\
\hline Public adm., defense & $1.60^{* * *}$ & $(0.25)$ & 0.55 & $(0.45)$ & $3.42^{* * *}$ & $(0.48)$ & -0.57 & $(0.96)$ \\
\hline Transportation, storage & $-0.31^{* * *}$ & $(0.06)$ & $-0.37^{* *}$ & $(0.16)$ & $-2.36^{* * *}$ & $(0.12)$ & $-3.16^{* * *}$ & $(0.24)$ \\
\hline Manufacturing & $-0.21^{* * *}$ & $(0.03)$ & $-0.23^{* *}$ & $(0.08)$ & $-0.59^{* * *}$ & $(0.06)$ & -0.00 & $(0.14)$ \\
\hline Mining & $0.64^{* *}$ & $(0.27)$ & 1.12 & $(0.88)$ & $1.35^{* *}$ & $(0.51)$ & -1.37 & $(1.56)$ \\
\hline Construction & $-0.55^{* *}$ & $(0.24)$ & -0.52 & $(0.60)$ & 0.29 & $(0.61)$ & -0.49 & $(1.45)$ \\
\hline Education & $-2.37^{* * *}$ & $(0.51)$ & $-3.31^{* * *}$ & $(0.78)$ & $-3.05^{* *}$ & $(1.33)$ & -1.46 & $(1.87)$ \\
\hline Professional, scientific & -0.04 & $(0.05)$ & $-1.11^{* * *}$ & $(0.21)$ & -0.07 & $(0.11)$ & -0.60 & $(0.46)$ \\
\hline Information, comm. & $-0.31^{* * *}$ & $(0.07)$ & $0.50^{* *}$ & $(0.17)$ & $-0.89^{* * *}$ & $(0.11)$ & $-1.28^{* * *}$ & $(0.31)$ \\
\hline Electricity, gas & 0.18 & $(0.18)$ & $-0.95^{* * *}$ & $(0.22)$ & -0.09 & $(0.50)$ & -0.91 & $(0.55)$ \\
\hline Finance, insurance & $0.53^{* * *}$ & $(0.08)$ & $-1.01^{* * *}$ & $(0.14)$ & $-0.24^{* *}$ & $(0.11)$ & $0.63^{* *}$ & $(0.30)$ \\
\hline
\end{tabular}

Notes: Industries sorted in ascending order of average hourly wage in February 2020. Robust standard errors in parentheses. $*, * *, * * *$ represent significance at $10,5,1$ percent. Dependent variable is employment change in percent. $\beta_{2}$ : coefficient on time dummy $D_{t}(\mathrm{Feb}) ; \gamma$ : coefficient on interaction term $D_{r}(\mathrm{DG}) \cdot D_{t}(\mathrm{Feb})$.

our data. The industry composition varies across regions and may introduce heterogeneous pre-trends, but the industry-by-industry estimation alleviates such concerns.

The first row shows the effect of the incipient COVID-19 epidemic on overall employment. Between the end of January and the end of February (from 11 confirmed cases to 3,150 nationwide), employment fell by 0.89 percent (not annualized) in Korea, shown by the estimate of $\beta_{2}$. To put this number in perspective, employment grew by an average of 0.23 percent per month (not annualized) from Jan 2018 to Jan 2020, and there is only negligible seasonality. Although causality cannot be established, it strongly suggests the effect of the incipient epidemic on the entire Korean economy. The effect was much stronger for DG, which accounted for 86.5 percent of the 3,150 total confirmed cases (there were no case in DG as of January 31). The estimated $\gamma$ shows that employment in DG fell at more than double the rate for the entire country, by 1.91 (0.89 plus 1.02) percent 
in a month. ${ }^{5}$ The estimate of $\gamma$ is the direct causal effect of the local epidemic on local employment, given the exogenous nature of the variation in confirmed infections by region.

Table 1 shows that the effects differ across industries, sorted in ascending order of average wage. Not surprisingly, accommodations/food service industries were hit hardest, not only nationwide ( -5.7 percent), but especially in DG (-15.2 percent), as people avoided contact-intensive services. They also happen to be the lowest-paying industry. Employment in education industries, which does not include public school teachers, also saw a large drop (2.4 percent nationwide and 5.7 percent in DG). Employment in arts/sports/recreation fell substantially nationwide (2 percent) but there was no additional effect from local infections. On the other hand, real estate shows a significant negative causal effect, although its employment went up weakly nationwide.

The right panel of Table 1 shows the cumulative employment effect from the end of January to the end of March (9,569 cases nationwide, 83.4 percent in DG) from a regression of bimonthly data. Employment fell by 2.1 percent nationwide over two months (not annualized) and by 3.3 percent in DG. The Korean government delayed the start of the school year on March 2 and implemented enhanced social distancing measures on March 22, both at the national level. As a result, the estimated $\beta_{2}$ partly reflects the effect of government policies and the $\gamma$ estimate is likely biased downward. The estimates of the causal effect of the local outbreak $\gamma$ are similar to those in the left panel, with accommodation/food services showing the largest additional employment decrease in DG. Wholesale/retail, health/social services, transportation/storage industries show a significant additional drop in DG in March (1.8, 3.4 and 3.2 percent, respectively), much more so than in February, suggesting a delayed impact. On the other hand, the differential effect on education industries in DG disappear in March, which is not surprising given the nationwide delay of the school year.

To unpack the decline in employment, we estimate equation (1) with three alternative dependent variables: the monthly number of hires, separations and vacancies, all as a percentage of the previous month's employment. Table 2 shows that the February employment drop in DG caused by the outbreak is entirely driven by decreased hiring and not by increased separations (layoffs and quits).

\footnotetext{
${ }^{5}$ Regional LFSE data are available only from January 2018, implying that $\gamma$ compares 25 monthly observations with one (January 2018 to January 2020 vs. February 2020). This is a small sample, especially post COVID-19, but most of our estimates are still highly significant.
} 


\section{Table 2: COVID-19 effect on hiring and separations}

\begin{tabular}{cccccc}
\hline \multicolumn{2}{c}{ Employment } & & Hires & Separations & Vacancies \\
$\beta_{2}$ & $\gamma$ & & $\gamma$ & $\gamma$ & $\gamma$ \\
\cline { 1 - 4 } \cline { 5 - 7 }$-0.89^{* * *}$ & $-1.02^{* * *}$ & & $-1.08^{* * *}$ & -0.24 & $-0.21^{* * *}$ \\
$(0.09)$ & $(0.17)$ & & $(0.23)$ & $(0.19)$ & $(0.05)$
\end{tabular}

Notes: Robust standard errors in parentheses. ${ }^{*},{ }^{* *},{ }^{* * *}$ represent significance at $10,5,1$ percent. Dependent variables are employment changes, new hires, separations, and vacancies, all as percent of the previous month's employment. $\beta_{2}$ : coefficient on time dummy $D_{t}(\mathrm{Feb}) . \gamma$ : coefficient on interaction term $D_{r}(\mathrm{DG}) \cdot D_{t}(\mathrm{Feb})$.

Table 3: Effect on employment by establishment size (selected industries)

\begin{tabular}{lcccccc}
\hline & \multicolumn{2}{c}{ Small } & \multicolumn{2}{c}{ Medium } & \multicolumn{2}{c}{ Large } \\
& $\gamma$ & \multicolumn{2}{c}{$\gamma$} & $\gamma$ \\
\hline Total & $-2.29^{* * *}$ & $(0.26)$ & 0.10 & $(0.26)$ & $0.77^{* *}$ & $(0.27)$ \\
\hline Accommodation, food svc. & $-10.04^{* * *}$ & $(0.63)$ & $-3.38^{* * *}$ & $(0.93)$ & $\cdot$ & \\
Real estate & -1.51 & $(1.03)$ & -0.80 & $(1.03)$ & $-12.71^{* * *}$ & $(3.45)$ \\
Health, social svc. & $-1.13^{* * *}$ & $(0.28)$ & $-1.49^{* * *}$ & $(0.30)$ & 0.18 & $(0.28)$ \\
Wholesale, retail & -0.22 & $(0.36)$ & $0.63^{*}$ & $(0.32)$ & $-1.16^{* *}$ & $(0.42)$ \\
Transportation, storage & $-0.81^{* *}$ & $(0.39)$ & -0.23 & $(0.39)$ & $2.36^{* * *}$ & $(0.58)$ \\
Manufacturing & $-0.75^{* * *}$ & $(0.11)$ & $0.24^{* *}$ & $(0.10)$ & 0.02 & $(0.13)$ \\
Education & $-10.46^{* * *}$ & $(1.22)$ & 0.85 & $(1.29)$ & 1.17 & $(1.20)$ \\
Professional, scientific & $-1.79^{* * *}$ & $(0.37)$ & 0.11 & $(0.38)$ & $-0.94^{* *}$ & $(0.43)$ \\
Information, comm. & $0.95^{* *}$ & $(0.38)$ & -0.27 & $(0.35)$ & $2.42^{* *}$ & $(1.10)$ \\
\hline
\end{tabular}

Notes: Selected industries sorted in ascending order of average hourly wage in February 2020. Robust standard errors in parentheses. ${ }^{*}, * *, * * *$ represent significance at 10, 5, 1 percent. Dependent variable is percentage employment change. Small, medium, and large denote establishments with fewer than 30 , between 30 and 299, and 300 or more employees, respectively. $\gamma$ : coefficient on interaction term $D_{r}(\mathrm{DG}) \cdot D_{t}(\mathrm{Feb})$ by establishment size category.

The top row of Table 3 shows that the causal effect of the local outbreak disproportionately affected small establishments (fewer than 30 employees) while if anything large establishments (300 or more employees) increased employment (first row) between January and February in DG. This result is partly driven by industrial composition: Most establishments in accommodation/food services, the industry hardest hit, are small. However, even within industries, small establishments lost employment by more than large establishments, especially in accommodation/food services and education, the two industries showing the largest causal impact in Table 1. In fact, in transportation/storage and information/communication industries, large establishments increased employment significantly in response to the local outbreak. The lone exception is the real estate industry, where the negative effect was concentrated among large establishments. 
Table 4: Employment, non-participation and unemployment

\begin{tabular}{|c|c|c|c|c|c|}
\hline \multicolumn{2}{|c|}{ Employment } & \multicolumn{2}{|c|}{ Non-participation } & \multicolumn{2}{|c|}{ Unemployment } \\
\hline$\beta_{2}$ & $\gamma$ & $\beta_{2}$ & $\gamma$ & $\beta_{2}$ & $\gamma$ \\
\hline $\begin{array}{c}-0.64^{* * *} \\
(0.19)\end{array}$ & $\begin{array}{c}-2.53^{* * *} \\
(0.34)\end{array}$ & $\begin{array}{c}0.72^{* * *} \\
(0.11)\end{array}$ & $\begin{array}{c}1.13^{* * *} \\
(0.22)\end{array}$ & $\begin{array}{c}0.12 \\
(0.12)\end{array}$ & $\begin{array}{l}-0.15 \\
(0.20)\end{array}$ \\
\hline
\end{tabular}

Notes: Robust standard errors in parentheses. ${ }^{*},{ }^{* *},{ }^{* * *}$ represent significance at $10,5,1$ percent. Dependent variable is employment change in percent, percentage point change in labor force nonparticipation rate, and percentage point change in unemployment rate. $\beta_{2}$ : coefficient on time dummy $D_{t}$ (Mar). $\gamma$ : coefficient on interaction term $D_{r}(\mathrm{DG}) \cdot D_{t}(\mathrm{Mar})$.

\subsection{Household survey data (EAPS)}

We now turn to our estimates from EAPS, the household survey that provides more worker-side information. We still use the estimation equation (1), but now $i$ indexes a demographic group and the time dummy is $D_{t}($ Mar), because the first post-Shincheonji survey was as of March 15. This is one week before the launching of the social distancing advisory campaign, but after the decision to delay the beginning of the school year on March 2 .

Table 4 shows that employment fell by 0.6 percent nationwide and by 3.2 (0.64 plus 2.53) percent in DG between February 15 and March 15 (not annualized). These numbers are not directly comparable to the February LFSE estimates (0.89 and 1.91), because of the newly confirmed infections between February 28 (the LFSE survey date) and March 15, and also because EAPS includes the self-employed, not included in the LFSE. ${ }^{6}$ One noteworthy result is that the fall in employment did not manifest as a rise in unemployment, either nationwide or in DG. People who left employment instead reported themselves as non-participants. One possible explanation is that they are waiting out the epidemic rather than searching for jobs in the midst of it. Alternatively, they may be expecting to return to their previous job and are thus not searching for jobs, such as if they were furloughed. ${ }^{7}$

Table 5 shows the nationwide change in employment, $\beta_{2}$, and the causal effect of DG's outbreak on local employment, $\gamma$, by occupation, educational attainment, gender, age and employment type. We focus on the causal effect of local outbreaks, $\gamma$. The first panel, which stratifies the labor force by one-digit

\footnotetext{
${ }^{6}$ EAPS definition of "self-employed" is non-employers with zero employees, who are not covered by the establishment survey of employers.

${ }^{7}$ While private furloughs exist, the Korean government did not implement any public furlough schemes that some of their European counterparts did.
} 
occupations, shows that service, sales, and craft workers were hit the hardest by the outbreak in DG. In contrast, the number of managers actually increased by more than 7 percent. The next two panels show that by education, less educated workers lost disproportionately more jobs, while by gender, the direct causal effect was larger for men (-2.8 vs. -2.2 percent). ${ }^{8}$ By age, the causal effect is largest for younger workers (those in their twenties or younger), followed distantly by those in their forties and those aged 60 or older. Finally, by employment type, job losses were heavily concentrated among temporary workers and unpaid family workers, although self-employment also fell by 2.3 percent. The overall pattern that emerges from Table 5 is that workers of lower socioeconomic status were much more vulnerable to the local outbreak.

But are the unequal employment effects across different worker groups driven by industrial composition? That is, do the effects differ solely because certain types of workers are over-represented in industries more exposed to the COVID19 shock? We answer this question by decomposing the causal employment effect of a given demographic group, $\gamma$, into an industry component (that differs only between industries) and a group-specific component (that varies within industries). A potential problem is that the EAPS only provides data by industry or by region, but not by industry-and-region. We sidestep this issue by computing what the effect on each group's employment would have been if a shock to an industry in DG, estimated off LFSE in Table 1, equally affected all demographic groups within it, which is the industry-specific effect. ${ }^{9}$ Then for each demographic group, the between-industry effect is computed as the average of industry-specific effects using as weights each group's nationwide employment share by industry in February, only available from EAPS, times employment share by industry for all workers in DG in January, only available from LFSE. The difference between the actual effect in Table 5 and this between-industry effect is the within-industry or group-specific effect. ${ }^{10}$ Figure 3 shows the total effect and the within-industry effect on the employment of worker groups. We focus on the causal effect of local outbreaks $\gamma$ on the right panel.

By occupation, the positive employment effect on managers is entirely an occupation-specific phenomenon - if anything, the hardest hit industries had

\footnotetext{
${ }^{8}$ But nationwide, the drop in women's employment was larger (-1.4 vs. -0.1 percent).

${ }^{9}$ As discussed earlier, the magnitude of $\gamma$ for all workers is larger in EAPS than in LFSE. Thus we also rescale LFSE's industry-specific $\gamma^{i}$ 's by the ratio between the EAPS and LFSE estimates for all workers.

${ }^{10}$ We do a similar exercise for the nationwide estimate $\beta_{2}$ as well, for which we encounter no such data problem since EAPS reports employment of each demographic group by industry.
} 
Table 5: COVID-19 effect on employment by worker characteristics

\begin{tabular}{|c|c|c|c|c|c|c|}
\hline \multirow[b]{2}{*}{ By occupation } & \multirow[t]{2}{*}{$\begin{array}{c}\text { Hourly wage } \\
\text { (Aug 2019) }\end{array}$} & \multirow[t]{2}{*}{$\begin{array}{c}\text { Share } \\
\text { (percent) }\end{array}$} & \multicolumn{2}{|l|}{$\beta_{2}$} & \multicolumn{2}{|l|}{$\gamma$} \\
\hline & & & & & & \\
\hline Managers & 44.9 & (1.4) & 0.46 & $(0.51)$ & $7.42^{* * *}$ & (1.01) \\
\hline Professionals & 25.8 & $(20.8)$ & $-2.02^{* * *}$ & $(0.11)$ & $-2.30^{* * *}$ & $(0.32)$ \\
\hline Clerks & 23.0 & $(17.7)$ & $-1.43^{* * *}$ & $(0.10)$ & $-1.21^{* * *}$ & $(0.35)$ \\
\hline Service workers & 12.1 & $(11.9)$ & $-4.80^{* * *}$ & $(0.20)$ & $-5.51^{* * *}$ & $(0.45)$ \\
\hline Sales workers & 15.0 & $(11.2)$ & $-2.15^{* * *}$ & $(0.16)$ & $-5.96^{* * *}$ & $(0.50)$ \\
\hline Craft and related trades & 17.9 & $(8.9)$ & $1.07^{* * *}$ & $(0.28)$ & $-5.93^{* * *}$ & $(0.49)$ \\
\hline Machine operators & 17.1 & $(11.3)$ & $-1.01^{* * *}$ & $(0.13)$ & 0.61 & $(0.40)$ \\
\hline Elementary workers & 11.5 & $(12.6)$ & -0.44 & $(0.68)$ & $-2.33^{*}$ & $(1.29)$ \\
\hline \multicolumn{7}{|l|}{ By education } \\
\hline Middle school & 11.7 & (13.6) & 0.39 & $(0.45)$ & $-5.00^{* * *}$ & $(0.71)$ \\
\hline High school & 15.2 & $(38.5)$ & $-1.82^{* * *}$ & $(0.13)$ & $-3.79^{* * *}$ & $(0.34)$ \\
\hline College & 24.0 & $(47.9)$ & $-0.68^{* * *}$ & $(0.10)$ & $-2.37^{* * *}$ & $(0.16)$ \\
\hline \multicolumn{7}{|l|}{ By gender } \\
\hline Male & 21.8 & $(57.2)$ & -0.07 & $(0.14)$ & $-2.82^{* * *}$ & $(0.23)$ \\
\hline Female & 16.1 & $(42.8)$ & $-1.40^{* * *}$ & $(0.26)$ & $-2.19^{* * *}$ & $(0.53)$ \\
\hline \multicolumn{7}{|l|}{ By age } \\
\hline $10-19$ & 9.6 & $(0.8)$ & $-21.58^{* * *}$ & $(1.64)$ & $-12.55^{* * *}$ & $(3.68)$ \\
\hline $20-29$ & 14.5 & $(14.0)$ & $-3.64^{* * *}$ & $(0.19)$ & $-6.51^{* * *}$ & $(0.52)$ \\
\hline $30-39$ & 20.6 & $(20.6)$ & $-1.60^{* * *}$ & $(0.10)$ & -0.23 & $(0.26)$ \\
\hline $40-49$ & 22.5 & $(24.1)$ & $-0.45^{* * *}$ & $(0.08)$ & $-3.44^{* * *}$ & $(0.16)$ \\
\hline $50-59$ & 21.7 & $(23.8)$ & $-0.78^{* * *}$ & $(0.16)$ & $-1.25^{* * *}$ & $(0.26)$ \\
\hline $60+$ & 14.0 & $(16.8)$ & $2.41^{* * *}$ & $(0.87)$ & $-3.35^{* *}$ & $(1.26)$ \\
\hline \multicolumn{7}{|l|}{ By employment type } \\
\hline Regular worker & 22.2 & $(54.4)$ & $-0.48^{* * *}$ & $(0.07)$ & $-0.56^{* * *}$ & $(0.18)$ \\
\hline Temporary worker & 12.6 & $(21.6)$ & $-4.76^{* * *}$ & $(0.56)$ & $-6.87^{* * *}$ & $(0.96)$ \\
\hline Employer & $\cdot$ & $(5.4)$ & $-3.61^{* * *}$ & $(0.26)$ & $-1.86^{* *}$ & $(0.82)$ \\
\hline Self-employed & . & $(15.0)$ & $2.84^{* * *}$ & $(0.29)$ & $-2.26^{* * *}$ & $(0.42)$ \\
\hline Unpaid family worker & . & $(3.6)$ & $6.58^{* * *}$ & $(0.96)$ & $-12.66^{* * *}$ & $(1.67)$ \\
\hline
\end{tabular}

Notes: Robust standard errors in parentheses. ${ }^{*},{ }^{* *},{ }^{* * *}$ represent significance at $10,5,1$ percent. Dependent variable is employment change in percent. $\beta_{2}$ : coefficient on time dummy, $D_{t}(\mathrm{Mar}) . \gamma$ : coefficient on interaction term $D_{r}(\mathrm{DG}) \cdot D_{t}(\mathrm{Mar})$. Hourly wage in thousand KRW (approximately 0.82 USD). Shares of the categories are from January 2020. 
Fig. 3: Effect on employment by worker characteristic: within and between industries

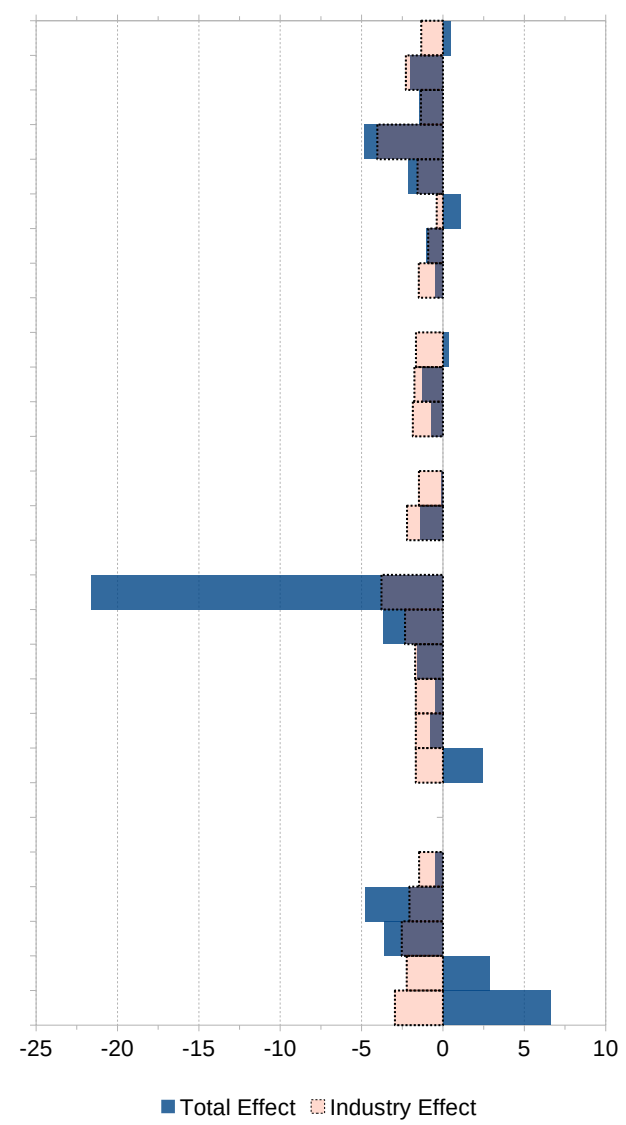

(a) National $\left(\beta_{2}\right)$

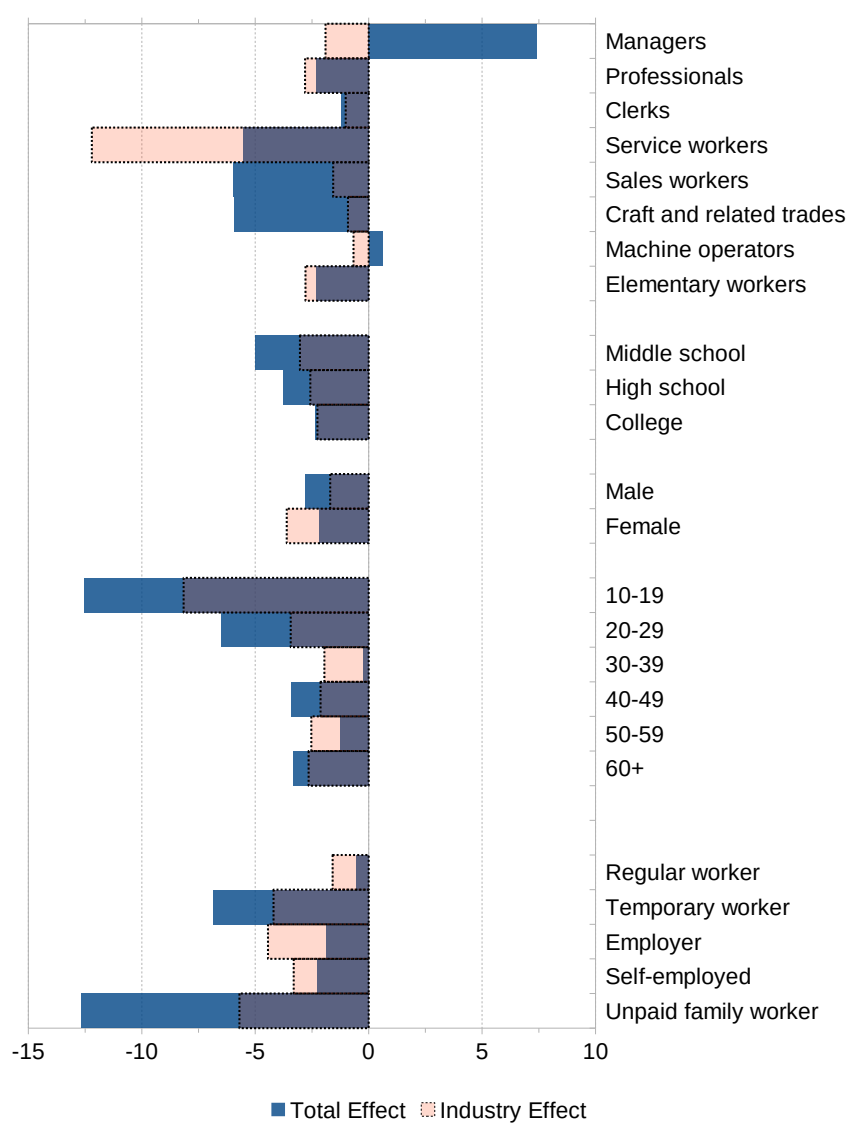

(b) DG $(\gamma)$

Notes: The dark bars represent the estimates from Table 5. The light bars represent the implied coefficients if for each each demographic group, employment changes were solely due to industrial effects only, estimated in Table 1. 
more managers than other industries (i.e., a negative between-industry effect on manager employment). Similarly, the industry effect alone would have cut service worker employment by more than 10 percent, but it was partly offset by a positive occupation-specific effect on service workers. Sales workers, on the other hand, were negatively affected by both the industry effect and the occupationspecific effect. That is, industries with larger drops in employment had relatively more sales workers, and at the same time, the local outbreak disproportionately destroyed more sales jobs, even within industries.

By gender, comparing the light bars, we see that industries that were negatively hit had a larger presence of women than men. However, the within-industry effect is actually positive for women while negative for men, leading to our earlier observation that the causal effect of the outbreak destroyed men's jobs more than women's.

Next, the figure shows that younger workers were not only more likely to work in industries that experienced larger employment losses, but also more exposed to the COVID-19 shock regardless of the industry in which they worked. For those 60 or older, the causal effect on their employment turns out to be almost entirely accounted for by the between-industry effect.

Finally, the large drop in the employment of temporary workers and unpaid family workers caused by the local outbreaks are nearly evenly divided into the between- and the within-industry effects. Not only did such workers tend to be employed in vulnerable industries, but they also faced similar disadvantages even within a given industry.

In summary, this decomposition exercise shows that the large employment losses experienced by the less educated, young workers and temporary workers were not only caused by their larger presence in industries hit harder by the COVID-19 shock. In addition, while women were over-represented in more vulnerable industries, the within-industry effect was such that men were more exposed to a causal drop in employment from local outbreaks.

\section{Fear of COVID-19 vs. Lockdowns}

\subsection{Impact on total employment}

Our estimate of the causal effect parameter $\gamma$ allows us to calculate how many jobs are destroyed solely due to private responses to incremental COVID-19 infections in the absence of mandatory lockdowns. The cleanest estimate of 
$\gamma$ is -1.02 , reported in Table 1 from the February LFSE, the establishment-side survey. Cumulative infection rates through February 28 were 0.39 per thousand in DG and less than 0.01 per thousand nationwide, excluding DG. Linearly extrapolating from our $\gamma$ estimate, we find that a one per thousand increase in infections causes a 2.68 percent drop in employment. ${ }^{11}$ Using our estimate from the March EAPS, the household survey, we find that a one per thousand increase in infections causes a 1.85 percent drop in employment. ${ }^{12}$ This is somewhat smaller than the calculation based on the February LFSE, possibly because the nationwide delay of the school year on March 2 biases the estimated causal effect downward.

These numbers based on our causal estimate, free of any contamination from mandatory lockdown effects, can be compared to observed labor market outcomes in the United States and the United Kingdom. Relative to Korea, both countries experienced very high infection counts with country-wide outbreaks, and implemented large-scale lockdowns in response. ${ }^{13}$ Since both countries implemented lockdowns almost at the same time as confirmed cases began to spiral upward, it is not possible to estimate a causal effect such as our $\gamma$. So we instead compute their counterparts to the overall effect $\beta_{2}$. In the US, Cajner et al. (2020) report a 14-percent decline in active employment between February 15 and April 18, 2020, using ADP payroll data. The cumulative infection count for the US on April 18 was 738,913, or 2.3 per thousand, implying that a one per thousand increase in infection counts is associated with a 6.2-percent decline in employment, a little more than double our causal estimate from Korea. Another estimate of employment losses in the US comes from Tedeschi and Bui (2020), who report a 12-percent employment decline between March 1 and April 18 from Civis Analytics. This implies that a one per thousand increase in infection counts is associated with a 5.3-percent decline in employment, a number between our causal estimate and the one implied from the ADP data. For the UK, Gardiner

\footnotetext{
${ }^{11}$ The cumulative infection rates through March 31 were 1.56 per thousand in DG and 0.034 per thousand nationwide, excluding DG. Linearly extrapolating from the $\gamma$ estimate, a one per thousand increase in infections causes a 0.8 percent drop in employment. The March 31 effect is smaller than February 28's partly because the nationwide policies in March attenuated the causal effect of local outbreaks.

${ }^{12}$ Cumulative infection rates through March 15 were 1.4 per thousand in DG and 0.02 per thousand nationwide, excluding DG.

${ }^{13}$ In the US, lockdown decisions were made by local governments. Forty-two states issued stay-at-home orders of varying degrees of intensity. Arkansas, Iowa, Nebraska, North Dakota, South Dakota, Oklahoma, Utah, and Wyoming never issued state-wide orders, but some of their cities still implemented localized lockdowns. The UK mandated a nation-wide lockdown, but each country had some discretion on when to ease restrictions.
} 
and Slaughter (2020) estimate that employment fell by 19 percent (15 percent furloughed plus 4 percent unemployed) based on data collected between May 6 to 11. The cumulative infection count on May 10 was 3.2 per thousand, implying that a one per thousand increase in infection counts is associated with a 5.9-percent decline in employment.

The three calculations from the US and the UK yield three estimates that are strikingly close to one another, and they are roughly double the relationship between employment and infection counts implied by our causal estimate without lockdowns. Thus, our results show that even without lockdowns, infection counts alone would have caused employment losses half as large. Furthermore, lockdowns are implemented to contain the epidemic. Suppose that infection counts would have reached twice the levels we observed in those countries had they not implemented any lockdown. ${ }^{14}$ Then our causal estimate implies that the resulting employment losses in the absence of lockdowns would have been even larger than currently observed employment losses in the US and the UK.

\subsection{Impact across industries and demographic groups}

Government implementation of lockdowns specify which activities are essential and non-essential. As a result, any negative employment effects from a lockdown would be heterogeneous across industries by design, and to the extent that the demographic composition of workers differ across industries, the effects would also be heterogeneous across demographic groups.

We compare the pattern of the causal employment effects from local outbreaks without lockdowns (Tables 1, 3, 5 and Figure 3) with national patterns with lockdowns in the US reported by Cajner et al. (2020). First, with or without lockdowns, nearly the same set of industries are hit hardest by the epidemic, including accommodation/food services, real estate, transportation/storage and education. One exception is arts/sports/recreation, which fell significantly nationwide in both Korea and the US, but the causal effect (estimated from regional differences) is insignificant. Second, in both cases, small establishments are hit hardest, controlling for industry effects. Third, nearly the same sets of workers are disproportionately affected with or without lockdowns: low-skill workers, young workers, and those on temporary contracts. ${ }^{15}$ Finally, in both cases, the

\footnotetext{
${ }^{14} \mathrm{By}$ all accounts, this is a lower-bound of counterfactual infection counts had no control measures been put in place in those countries, e.g. https://covid19.healthdata.org.

${ }^{15}$ Coibion et al. (2020) also report this last fact for the US, and the UK data also shows the same pattern
} 
heterogeneous effects across workers are accounted for by both between-industry effects and within-industry effects. One difference is the effect by gender. As shown in Figure 3, the between-industry causal effect is larger for women, but the within-industry effect is larger for men so that male workers lose more jobs. In the US, largely due to the between-industry effect, female employment falls by more, as well in the UK. ${ }^{16}$

\section{Concluding Remarks}

We estimate the causal effect of COVID-19 infections on the labor market, exploiting regional variations in Korea. Our difference-in-differences estimate is uncontaminated by lockdowns, which were never pursued by the Korean government, capturing only the voluntary response by private businesses and consumers. Moreover, thanks to a successful test/trace/tracking strategy, total infection counts remained low in Korea and the epidemic was by and large contained to a single region, DG, which experienced a local outbreak triggered by reasons exogenous to any underlying economic factor.

Our main result that a one per thousand increase in confirmed infections causes a 2.7-percent decline in employment is about half the magnitude of noncausal estimates from the US or UK, which confound the direct effects from COVID-19 with lockdown effects. Moreover, the causal patterns we obtain across industries, establishment size classes, and workers' occupation, education, age and employment type tell us that the epidemic struck high-contact industries, small establishments, and workers of lower socioeconomic status the hardest. The causal patterns are very much in line with descriptive evidence from the US and UK as well. This suggests that the primary culprit of the COVID-19 recession is COVID-19 itself, rather than lockdowns, so that the lifting of lockdowns around the world may lead to only modest recoveries unless the infection rates fall. The best way to revive the labor market is to eradicate the virus.

(Gardiner and Slaughter, 2020).

${ }^{16}$ However, our nationwide estimate of $\beta_{2}$ shows that women lost more jobs than men in Korea, and that within-industry effects are much more positive for men than women. 


\section{Bibliography}

Andersen, A. L., E. T. Hansen, N. Johannsen, and A. Sheridan (2020, May). Pandemic, shutdown and consumer spending: Lessons from Scandinavian policy responses to COVID-19. Technical report, University of Copenhagen and CEBI.

Aum, S., S. Y. T. Lee, and Y. Shin (2020, May). Inequality of fear and selfquarantines: Is there a trade-off between GDP and public health? Working Paper 27100, NBER.

Born, B., A. Dietrich, and G. Mueller (2020, May). Do lockdowns work? A counterfactual for Sweden. Technical report, Covid Economics: Vetted and Real-time Papers.

Cajner, T., L. D. Crane, R. A. Decker, J. Grigsby, A. Hamins-Puertolas, E. Hurst, C. Kurz, and A. Yildirmaz (2020, May). The U.S. labor market during the beginning of the pandemic recession. Working Paper 27159, NBER.

Coibion, O., Y. Gorodnichenko, and M. Weber (2020, April). Labor Markets During the COVID-19 Crisis: A Preliminary View. Working Paper 27017, NBER.

Gardiner, L. and H. Slaughter (2020, May). The effects of the coronavirus crisis on workers: Flash findings from the Resolution Foundation's coronavirus survey. Technical report, Resolution Foundation.

Tedeschi, E. and Q. Bui (2020, May 13). America's employment losses might be slowing: Job tracker. The New York Times. 